\title{
Extracorporeal membrane oxygenation: The simplified weaning bridge
}

\author{
Vladimiro L. Vida, MD, PhD, Mauro Lo Rito, MD, Massimo A. Padalino, MD, PhD, and \\ Giovanni Stellin, MD, Padua, Italy
}

Extracorporeal membrane oxygenation (ECMO) is commonly used in children to allow recovery from post-cardiac surgical heart failure that is refractory to medical therapy or resuscitation. The overall survival after ECMO has been reported to be between $35 \%$ and $51 \%$ in institutions where a dedicated 24-hour in-house ECMO team is part of the surgical program. ${ }^{1-4}$ In pediatric cardiac centers with average volumes, however, a specialized ECMO team is often not available and a greater effort must be made to provide the best outcome for patients requiring mechanical circulatory support.

We describe an easy and reproducible technical solution for weaning patients from ECMO support. This method proved to be a safe and an effective solution in our institution, where a dedicated 24-hour in-house ECMO team is lacking.

\section{THE SIMPLIFIED WEANING BRIDGE}

After ECMO weaning criteria have been reached,${ }^{1-3}$ the simplified weaning bridge (a bridging tube $50 \mathrm{~cm}$ long and $2.5 \mathrm{~mm}$ in diameter) is placed between the patient and the ECMO circuit to allow flow recirculation (Figure 1). Heparin infusion (20 IU/kg/h, diluted to obtain an infusion rate of $5 \mathrm{~mL} / \mathrm{h}$ for each cannula) is then started to flush continuously both the arterial and the venous cannulas. A tubing clamp is then placed between the simplified weaning bridge and the heparin infusion lines, separating the patient's circulation from the ECMO circuit (Figure 1). ECMO circuit heparinization is accomplished with a bolus of heparin $(1000 \mathrm{U})$ and monitored every 3 hours to maintain an activated clotting time greater than 250 seconds. Patients are routinely monitored for the 24 hours after ECMO discontinuation, maintaining the ECMO recirculating next to the bed space in case of need, and then decannulated.

\footnotetext{
From the Division of Pediatric and Congenital Cardiac Surgery, University of Padua, Padua, Italy.

Disclosures: Authors have nothing to disclose with regard to commercial support. Received for publication Aug 25, 2011; revisions received Nov 22, 2011; accepted for publication Dec 8, 2011; available ahead of print Feb 16, 2012.

Address for reprints: Vladimiro L. Vida, MD, PhD, Pediatric and Congenital Cardiac Surgery Unit, Via Giustiniani, 2-35100 Padua, Italy (E-mail: vladimirovida@ yahoo.it).

J Thorac Cardiovasc Surg 2012;143:e27-8

$0022-5223 / \$ 36.00$

Copyright (C) 2012 by The American Association for Thoracic Surgery

doi:10.1016/j.jtcvs.2011.12.065
}

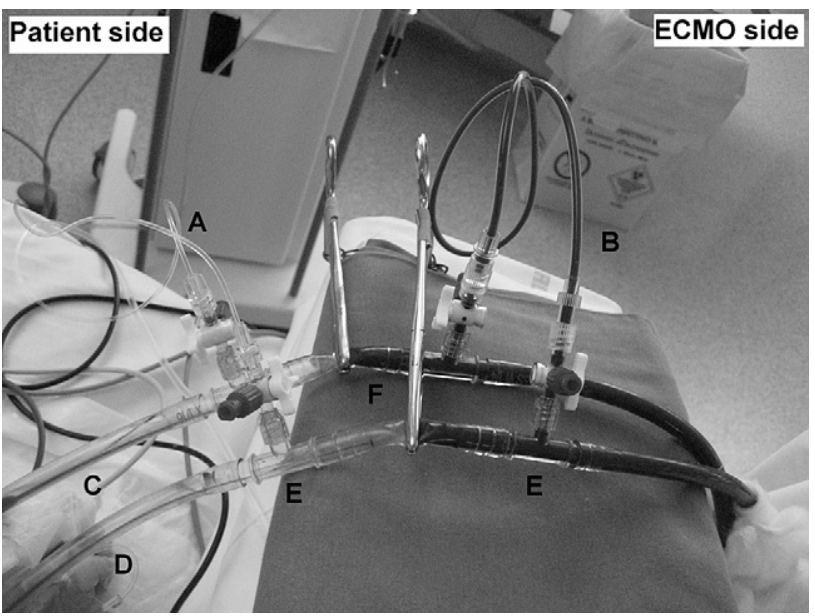

FIGURE 1. The simplified weaning bridge: $(A)$ heparin infusion lines; $(B)$ extracorporeal membrane oxygenation $(E C M O)$ bridge; $(C)$ arterial line flushed by heparin infusion; $(D)$ venous line flushed by heparin infusion; $(E)$ straight connector with Luer locks; $(F)$ tubing clamps for separating the extracorporeal membrane oxygenation circuit from the patient.

\section{RESULTS}

From January 2010 to August 2011, a total of 30 consecutive patients needed ECMO support in our unit. Indications for ECMO support were as follows: (1) failure of weaning from cardiopulmonary bypass $(\mathrm{n}=17 ; 57 \%)$ and (2) postoperative cardiac arrest unresponsive to medical treatment $(\mathrm{n}=13 ; 43 \%)$.

Eighteen of these patients $(60 \%)$ were disconnected from the ECMO by using our simplified weaning bridge, after a median duration of mechanical support of 7 days (range, 1-29 days). After ECMO discontinuation, 7 of these patients $(7 / 18 ; 38.8 \%)$ required a second ECMO run with the same cannulas and ECMO circuit. The ECMO run was easily restarted by opening the tubing clamps, closing the Luer locks of the ECMO's bridge, and stopping heparin infusions into the patient's cannulas (Figure 1). We did not see any clot formation in the cannulas, nor were there any thromboembolic complications. Two of the patients who required a second ECMO run were eventually weaned from mechanical support (2/7; $28.6 \%$ ). ECMO weaning with decannulation was achieved in 13 of the 18 patients who were connected to the simplified weaning bridge $(72.2 \%)$, and 1 patient was weaned from ECMO without the simplified weaning bridge 
(1/12; 8.3\%). Overall, ECMO weaning with decannulation was achieved in 14 patients $(46.6 \%)$.

Three patients died in the hospital 9, 35, and 40 days after ECMO discontinuation and decannulation for septic shock ( 2 of them were in the bridge group). The overall survival at discharge was $36.6 \%$ (11/30 patients).

\section{DISCUSSION}

ECMO support is currently required to allow a patient's recovery after cardiac surgery, after cardiopulmonary arrest refractory to resuscitation maneuvers, or after severe respiratory damage. $^{3-5} \mathrm{~A}$ specialized 24-hour in-house ECMO team is usually necessary to monitor patient's parameters continuously to guarantee the best possible outcome ${ }^{1-4}$; this requires a great economic investment and is generally possible in large-volume pediatric heart centers with great financial resources.

The weaning from ECMO support is always a delicate phase in the management of heart and lung recovery, and constant observation of the patient's hemodynamic status is mandatory, together with continuous flushing of the circuit and cannulas when ECMO is temporarily stopped to prevent the risk of clot formation and systemic embolism. $^{2-3}$ In our unit, because of the lack of a dedicated 24-hour in-house ECMO team, a strict and tireless cooperation among cardiac surgeons, nursing personnel, and perfusionists is essential for buffering our limited resources. For these reasons, we have developed the simplified weaning bridge, which allows us to observe the patients during the first critical 24 hours after ECMO weaning with the ECMO circuit recirculating at the bed space and ready to be restarted in a few seconds if needed.

The simplified weaning bridge can be used without additional human and economic resources. With the bridge, ECMO can be restarted fast and safely (so long as it was not discontinued for any hemorrhagic or thromboembolic complications) just by removing 2 tubing clamps, without emergency resuscitation maneuvers or a new cannulation, thus obviating the need for surgeons or other specialized technicians. The introduction of the simplified weaning bridge into our therapeutic armamentarium allows us to be more liberal in the process of weaning patients from ECMO because of the easy possibility of restarting the support.

\section{References}

1. Thiagarajan RR, Laussen PC, Rycus PT, Bartlett RH, Bratton SL. Extracorporeal membrane oxygenation to aid cardiopulmonary resuscitation in infants and children. Circulation. 2007;116:1693-700.

2. Shuhaiber J, Thiagarajan RR, Laussen PC, Fynn-Thompson F, del Nido P, Pigula F. Survival of children requiring repeat extracorporeal membrane oxygenation after congenital heart surgery. Ann Thorac Surg. 2011;91:1949-55.

3. Kane DA, Thiagarajan RR, Wypij D, Scheurer MA, Fynn-Thompson F, Emani S, et al. Rapid-response extracorporeal membrane oxygenation to support cardiopulmonary resuscitation in children with cardiac disease. Circulation. 2010;122(11 Suppl):S241-8.

4. Aharon AS, Drinkwater DC Jr, Churchwell KB, Quisling SV, Reddy VS, Taylor M, et al. Extracorporeal membrane oxygenation in children after repair of congenital cardiac lesions. Ann Thorac Surg. 2001;72:2095-102.

5. Vida VL, Rubino M, Stellin G. Prolonged ECMO support for virus-induced cardiorespiratory failure early after cardiac surgery. Pediatr Cardiol. 2006;27: $122-3$.

\title{
Occult gastrointestinal bleeding in patients with a left ventricular assist device axial flow pump: Diagnostic tools and therapeutic algorithm
}

\author{
Vincenzo Tarzia, MD, ${ }^{\mathrm{a}}$ Carlo Dal Lin, MD, ${ }^{\mathrm{a}}$ Tomaso Bottio, MD, PhD, ${ }^{\mathrm{a}}$ Stefano Benvenuti, MD, ${ }^{\mathrm{b}}$ \\ Fausto Chilovi, MD, ${ }^{\mathrm{b}}$ and Gino Gerosa, $\mathrm{MD},{ }^{\mathrm{a}}$ Padova and Bolzano, Italy
}

\footnotetext{
From the Division of Cardiac Surgery, ${ }^{\text {a }}$ Department of Cardiac, Thoracic, and Vascular Sciences, Padova University, Padova, Italy; and the Gastroenterology Unit, ${ }^{\mathrm{b}}$ Bolzano Hospital, Bolzano, Italy.

Disclosures: Authors have nothing to disclose with regard to commercial support.

Received for publication July 7, 2011; revisions received Nov 23, 2011; accepted for publication Jan 6, 2012; available ahead of print Feb 3, 2011.

Address for reprints: Vincenzo Tarzia, Division of Cardiac Surgery, Department of Cardiac, Thoracic, and Vascular Sciences, University of Padua, Via Giustiniani, 2, 35128 Padova, Italy (E-mail: v.tarzia@gmail.com).

J Thorac Cardiovasc Surg 2012;143:e28-31

0022-5223/\$36.00

Copyright (c) 2012 by The American Association for Thoracic Surgery

doi:10.1016/j.jtcvs.2012.01.033
}

Gastrointestinal (GI) bleeding is a common and serious problem in patients with continuous-flow left ventricular assist devices (LVADs). ${ }^{1,2}$ Thus in a clinical context it is crucial to adopt the most effective diagnostic strategy and where possible use noninvasive procedures to limit the infective and hemorrhagic burden.

We report the case of a patient with significant GI bleeding after implantation of a Jarvik 2000 LVAD (Jarvik Heart, Inc, New York, NY). The sources of the bleeding were successfully identified by wireless PillCam SB capsule videoendoscopy (VCE) (Given Imaging, Yoqneam, Israel) 